\title{
Research on the Construction of Core Competitiveness of Yantai Enterprises in the Age of "Internet +"
}

\author{
Teng Xingqiang ${ }^{\mathrm{a}}$, Tong $\mathrm{Di}^{\mathrm{b}}$ \\ Yantai Nanshan University, China

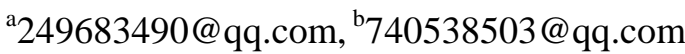

Keywords: Internet +, Core Competitiveness, Innovation Driven.

\begin{abstract}
With the formation of the Internet + new economic form, China's enterprises and the Internet are deeply integrated, relying on Internet information technology to achieve the transformation and upgrading by optimizing the production factors of the enterprise, updating the business system of the enterprise, and reconstructing the business model of the enterprise. Economic globalization has brought opportunities and challenges to Chinese enterprises. The market competition is extremely fierce. If enterprises want to survive, they must form their own core competitiveness. Yantai enterprises should conform to the trend of the times, use the Internet + thinking, build the core competitiveness of enterprises, and promote the sustainable development of enterprises.
\end{abstract}

\section{Introduction}

In 2015, the Chinese government proposed to develop an "Internet+" action plan to bring new development opportunities to traditional enterprises. In layman's terms, "Internet + " is "Internet + various traditional enterprises". It is the core feature of the development of information technology and Internet platform, which makes the Internet and traditional enterprises fully integrated. Yantai enterprises are the pillar industries that promote the economic development of Yantai. Yantai is located in the blue economic zone of Shandong Peninsula, and its economy is relatively developed. In the "Internet +" era, how the core competitiveness of Yantai enterprises integrates the "Internet + " thinking is a problem that every Yantai enterprise must solve. The new situation of strengthening the main body and expanding the competition field and formulating practical and feasible cultivation measures have positive and practical significance ${ }^{[1]}$.

\section{Core competitiveness theory and innovation drive theory}

\subsection{Core competence theory}

Core competitiveness refers to resources that can bring competitive advantage to enterprises, as well as the way of resource allocation and integration. As the resources of the enterprise change and the efficiency of configuration and integration increases, the core competitiveness of the enterprise will also change. With the power generated by core competitiveness, a company is likely to stand out in the fierce market competition, so that the value of products and services will be improved in a certain period of time.

\subsection{Innovation Drive Theory}

Innovation drive refers to the driving force and engine of economic growth, from relying on technology learning and imitation to relying mainly on independent design, R\&D and invention, and knowledge production and creation.

The innovation drive was first proposed by the famous management scientist Michael Porter. The essence of innovation drive is technological innovation. The innovation-driven content is to form a new industrial system with industrial innovation, form a complete technological innovation system with scientific and technological innovation, form a new market and economic growth point 
with product innovation, provide guarantee for economic innovation through institutional innovation, and form collaborative innovation with strategic innovation. system. "Internet + " takes the Internet as the core feature of enterprise information development, and the key is innovation.

\section{The status quo and problems of the core competitiveness of Yantai enterprises}

\subsection{The status quo of core competitiveness of Yantai enterprises}

The core competitiveness of an enterprise is different for different enterprises and different stages of development of different enterprises. Generally speaking, the core competitiveness of an enterprise refers to the most powerful core element of a company's competitive advantage. The core competitiveness of an enterprise is generally characterized by scale advantage, technological advantage, business model advantage, market advantage or brand advantage. Manufacturing companies, the most common core competitiveness is brand advantage and scale advantage; Internet companies, the most common is the business model advantage. Business models are also known as business models, profit models, and so on. For enterprises, the core competitiveness of different stages of development is also different. It may be at the beginning of development, the core advantage is only the business model or technical advantage; to a certain stage of development, it will be transformed into scale advantage, brand advantage, price advantage or industrial chain advantage ${ }^{[2] .}$

The three levels of Yantai's core competitiveness have problems in varying degrees. At the core level, Yantai enterprises do not have advanced value concepts to guide them. Enterprises pay attention to short-term interests and do not pay attention to the cultivation of good corporate culture. The specific performance is that the company emphasizes the company or personal interests one-sidedly, but lacks the awareness of serving the society and the public. The values of many companies overemphasize the construction of the material layer, while ignoring the inner needs of employees. From the perspective of organizational system and management, the organizational structure of Yantai enterprises is not scientific enough, and the corporate management structure is not vulnerable. The strategic management of most enterprises is not perfect and scientific. From the perspective of the outermost resource element level, Yantai enterprises have low technical level and insufficient innovation capability. The quality of the enterprise management team is low, and high-tech talents are scarce. The level of enterprise information is not high. The combination of these problems shows that the core competitiveness of Yantai enterprises is relatively weak at present, and the core competitiveness is faced with the difficulty of upgrading and the long time required for improvement.

\subsection{Problems facing the core competitiveness of Yantai enterprises}

The cultivation of the core competitiveness of Yantai enterprises is inseparable from the measurement of the core competitiveness index system of enterprises. The leading power includes social influence and orientation. The integration ability is based on market development and competition, and the source of brand competence is technological innovation and management. Referring to these three system standards, Yantai enterprises are currently facing three problems.

First, the company's leading power includes vision leadership, technology leadership and value leadership. It is the enterprise's vision, technology, management model, etc., which guides and drives the enterprise. These capabilities of the enterprise are in a weak position. The original living environment of the enterprise is basically open to domestic enterprises, competitors are familiar with each other, and the competitive environment is relatively simple. enterprises lack of leading international patent technology, technology application level is not high, technology gold content is generally low, especially new technologies, new materials The mechanization application is far from the developed countries ${ }^{[3]}$.

Second, the ability to integrate information resources is weak. In today's era, information flow is large and flow rate is fast, and informationization has become an inevitable requirement for the survival and development of enterprises. Business operators must pay close attention to all kinds of 
information, quickly analyze and process information, and make scientific decisions in a timely manner to achieve optimal management.

Third, corporate branding capabilities are the ability to shape corporate image, build quality projects, and achieve value-added brand value. In recent years, China's economy is running at a high speed, and the development and expansion of infrastructure construction. Most enterprises are still in the traditional operation and extensive intensive operation mode, regardless of output value or personnel. They are not focused on the creation of classic projects, and they do not pay attention to the social influence, reputation and popularity of corporate brands. The brand's ability to expand ${ }^{[4]}$.

\section{Yantai enterprise core competitiveness construction ideas}

\subsection{Cultivate innovative consciousness}

The key to "Internet +" is innovation. Only innovation can reflect the true value and significance of "Internet +". The innovation drive is the "Internet + " trait, and "Internet + " provides a new way of thinking for enterprise development. Through "Internet + ", the flexibility and innovation of the company should be fully reflected, and the new round of business opportunities will be realized from the consciousness and quickly used for the operation of the enterprise. "Made in China 2025" proposes to adhere to the basic policy of "innovation-driven, quality-first, green development, structural optimization, and talent-oriented", and adhere to "market-led, government-led, based on the current, long-term perspective, overall promotion, key breakthroughs,

\subsection{Perform technical upgrades}

Technology plays a very important role in the development of enterprises. Frontier technology can not only enable enterprises to have competitive advantages, but also better promote the development of enterprises and enhance their core competitiveness. Therefore, enterprises must continuously develop new products, increase the development and research of core technologies, clearly understand what their core technologies are, and rationally apply the core competitiveness of enterprises to pursue the diversification of product functions. And the quality of the product is oriented to meet the changing needs of customers. At the time of technology upgrade, the introduction of advanced equipment is a relatively simple means, but considering the cost, it will impose a heavy burden on SMEs. Starting from existing resources and equipment, it is feasible to upgrade at the existing technology and resource level. At the same time, it is possible to reorganize and optimize internal processes, which is another way to improve enterprise efficiency and improve technology ${ }^{[5] .}$

\subsection{Emphasis on brand building and own intellectual property rights}

Brand means high quality, high reputation and high efficiency. If enterprises want to remain invincible in the market competition, they must build their own brands. With the development of the market economy, the consumer brand awareness is enhanced, the role of the brand and the impact on the company is immeasurable. With the support of the brand, companies can use the brand to stimulate the value of the product. Without a brand, there is no competition, and if you are not competitive, you cannot stand in the market. Brand has become the main source and survival basis of corporate profits, and is the source of power for market innovation.

\subsection{Strengthen organizational learning and enhance core competitiveness}

Learning is endless. With the concept of lifelong learning and being widely accepted, the construction of learning organizations is regarded by enterprises as an important part of maintaining competitiveness in the business process. The society is progressing. If it is not eliminated in the trend of history, continuous learning is the best choice. Training is a common form of organizational learning. The organization provides employees with an enhanced platform while operating, using various forms or training or team development, giving employees a platform for learning and training, enabling employees to update their knowledge systems. Improve and better 
provide new ideas and methods for organizational management and development, promote the development of enterprises, and maintain and enhance the core competitiveness of enterprises.

\subsection{Integration of effective resources}

Resources are priceless. This resource refers not only to the internal resources of the enterprise, but also to the external resources of the enterprise. Enterprises are not independent in the market, and always have partners. The role of effective resources in the operation of a company is also great. Therefore, enterprises must integrate effective resources and integrate them.

\section{Conclusion}

The core competitiveness of an enterprise can help enterprises occupy a certain share in the market, which is related to the success or failure of business operations. We must realize that the formation of the core competitiveness of enterprises is not a one-off event. In the era of "Internet +", the information that enterprises can grasp, including the use of information, is constantly deepening, and we must maximize the "based on the existing situation." The Internet +" cross-border integration, innovation-driven, reinventing the structure, respecting humanity, opening up the ecology, connecting all the characteristics to build the core competitiveness of the enterprise, in order to promote the healthy and sustainable development of Yantai enterprises.

\section{References}

[1] Mo Xiaoquan. The Construction of Core Competitiveness of Logistics Enterprises Based on Low Carbon Economy Theory [J].Commercial Economic Research, 2018, 09, p.118-120.

[2] Sun Wei, Chen Zhibin, Huang Cong, Lu Wei, Deng Chao, GAO Rong. Research on "Internet + Convergence" of Tobacco Industry Enterprises [J]. China Market, 2018, 01, p. 154-155.

[3] Jie Qingqing. Analysis of the core competitiveness of enterprises under the Internet economy [J]. National Circulation Economy, 2017 (20): 36-37.

[4] Tao Jihua. Research on the Cultivation of Core Competitiveness of Construction Enterprises Based on "Internet +"[J].Journal of Zhunyin Institute of Technology, 2017, 05, p.91-95.

[5] Xie Xiaoyan. Reconstruction of Enterprise Core Competence in the Background of Mobile Internet [J]. Global Market Information Review, 2016, 21, p. 51-51. 